\title{
Integrated turbine-generators for hydropower plant - a review
}

\author{
Damian Liszka ${ }^{1 *}$, Dariusz Borkowski², and Stawomir Grądziel ${ }^{3}$ \\ ${ }^{1}$ Aqua-Tech Sp. Z o.o. Lipcowa 64 St., Trzebinia, Poland \\ ${ }^{2}$ Cracow University of Technology, Department of Electrical Engineering, Warszawska 24 St., Cracow, Poland \\ ${ }^{3}$ Cracow University of Technology, Department of Energy, Warszawska 24 St., Cracow, Poland
}

\begin{abstract}
The paper provide a comprehensive review on water turbine integrated with electrical generator. The integration consists in combining the generator with the turbine in one device without the use of a gearbox. The practical implementations of these solutions date back to the 1980s and are more and more common. Such a solution gives a wide possibility of integration and reduction of costs of the hydro unit, however, due to certain technological problems, it is not widely available. This article classifies the different types of integration and analyses it from a technical and economic point of view. Practical implementations and operational problems were also shown.
\end{abstract}

\section{Introduction}

The article presents the technical possibilities of the integration of a water turbine with a generator. The focus was on water turbines with variable speed synchronous generators, the turbine module of which can be adjusted according to the flow and water level in the river. Turbines with a generator on the same shaft were deployed in several dams between 1940 and 1950 and are now regaining interest in Central Europe.

The review covers existing solutions for integrating a water turbine with an electric generator. On the basis of the available scientific literature and practical knowledge, the properties of these solutions are presented. Particular attention was given to technical aspects and operational features. These analyses is the basis for proposing an integration solution concept that meets the design requirements, containing the beneficial features of the water-to-electricity conversion system with the elimination of known disadvantages and operational problems.

The standard machine solution in low head hydroelectric power plants is a turbine connected via a gear increasing speed to an asynchronous generator (usually the squirrel cage induction machine). This solution is commonly used and exploited. A multielement energy generation system requires the construction of power plant buildings and their protection against flooding. The cost of hydrotechnical construction for low heads is $50-70 \%$ of the total investment. In the case of the lowest heads, the classic solution excludes the economic viability of the construction. A significant disadvantage of using a gearbox is the mechanical losses generated by the gearbox. The use of oils and greases also does not comply with the current legal regulations. A cheap asynchronous generator in $75 \%$ of power operates with the rated efficiency, while its electrical losses significantly increase by up to $60 \%$ below. Advantages include the availability of spare parts and the simplicity of renovation and maintenance.

L.F. Harza, who in 1919 patented [1] his own solution and made real prototypes in the 1: 1 scale of these machines, is responsible for the first Publisher correct integration of a water turbine with a generator. Their installation in hydrotechnical facilities, despite careful execution, did not bring success due to problems with moisture and damage to the windings of generators [2]. For many years, this solution has been the goal of various companies involved in the production and operation of rotating machines, consequently a number of studies and patents for the same device have been created around the world.

The first tubular turbines were put into operation in 1936 in the Polish city of Rościno by the Swiss turbine manufacturer Escher Wyss (now Andritz Hydro). The development of rotating machinery has since led to advanced tubular turbine technology integrated into the generator. The compact structure of the machine can be ensured by placing the generator in a sealed casing (bulb) axially to the turbine (Fig. 1).

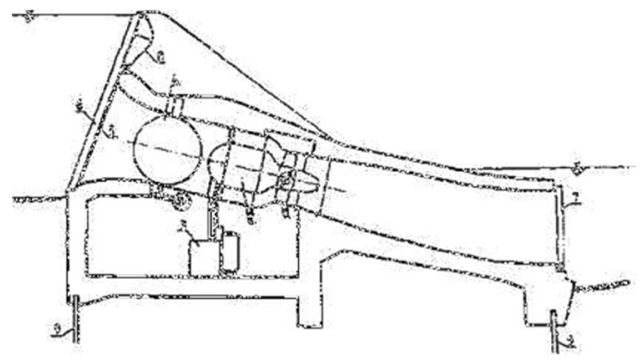

Fig. 1. SHPP Rościno Bulb turbine [3]

\footnotetext{
* Corresponding author: liszkadamian@gmail.com
} 
Such solutions are most often based on a cage induction generator, the rotational speeds of which are high, and for low and the lowest heads it is necessary to use a gear that multiplies the revolutions. Placing the gear lubricated mostly with oil inside the bulb poses a risk of lubricating oil leakage and contamination of the river. Such a design of low-pitched low-power machines limits the flow cross-section and causes significant disturbances in the water flow in the hydraulic channels of the machine, which reduces the efficiency of the assembly. For small machines, there are also problems with the dampening of the generators placed inside the bulb when the machine is at a standstill. Depending on the version, there are different types of integrated tubular turbines, which differ mainly in the arrangement of the generator.

There are many design solutions for integrating a water turbine and an electric generator in the literature. Due to the possibility of technical analysis, only the implemented solutions, i.e. those made and operated in real hydroelectric facilities, are presented.

\section{Full integration}

In order to reduce the dimensions of the machine and at the same time eliminate the problem of tightening the hydraulic section of the machine, it is to place a water turbine inside the rotor of the electric generator, so called full integration (Fig. 2). A synchronous generator with permanent magnets is used here due to the possibility of eliminating the gears and greater efficiency of the generator in a wide range of loads. The first such solutions appeared in the 1940s [4-5]. These were low power $(<1 \mathrm{MW})$ facilities and had problems with the sealing between the stator and rotor.

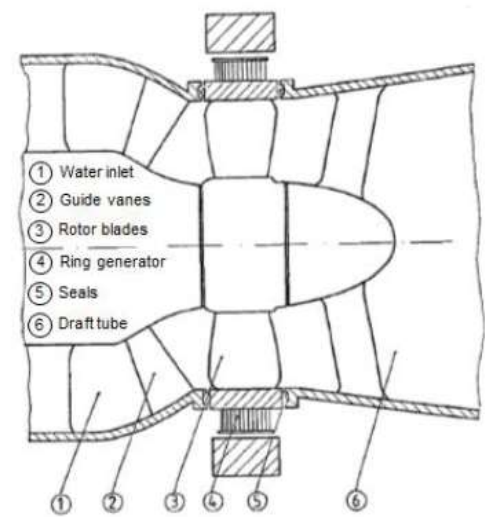

Fig. 2.Cross-section of the integrated STRAFLO-turbine [4]

The first facility with high power (100MW) containing 10 integrated hydro sets based on a propeller turbine with adjustable steering wheels was the power plant on the Rhein River (Laufenburg, Germany), established in 1987 [6].

Another solution was made by the Austrian company VA TECH HYDRO GmbH, called StrafloMatrix [7-9] and is intended for small hydropower plants (Fig. 3). Two units (300 kVA and $700 \mathrm{kVA})$ were made and installed at the Agonitz hydropower plant on the Steyr River in Austria.
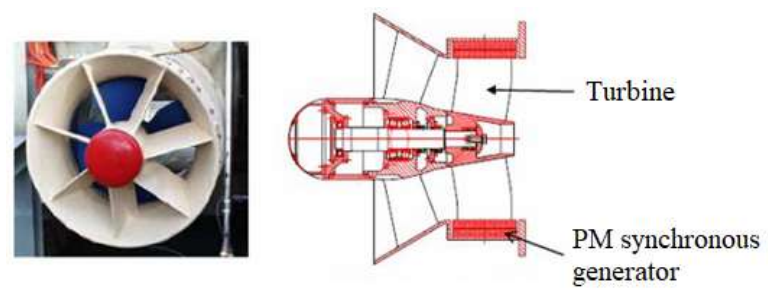

Fig. 3. Cross-section and view of an integrated turbine of StrafloMatrixVA TECH HYDRO GmbH [9].

A similar solution for small hydropower plants was installed at the AKWA power plant on the Biała Głuchołaska river near Nysa (Poland) (Fig. 4) [10]. There are two parallel hydro units with a total power of $150 \mathrm{~kW}$. The energy conversion system is also based on a propeller turbine and a synchronous generator with permanent magnets. In this solution, instead of the turbine rotor blade control system, a variable rotational speed was used through the use of a power electronic converter. This solution has been thoroughly tested and analysed by among others the authors of this study [11-14].

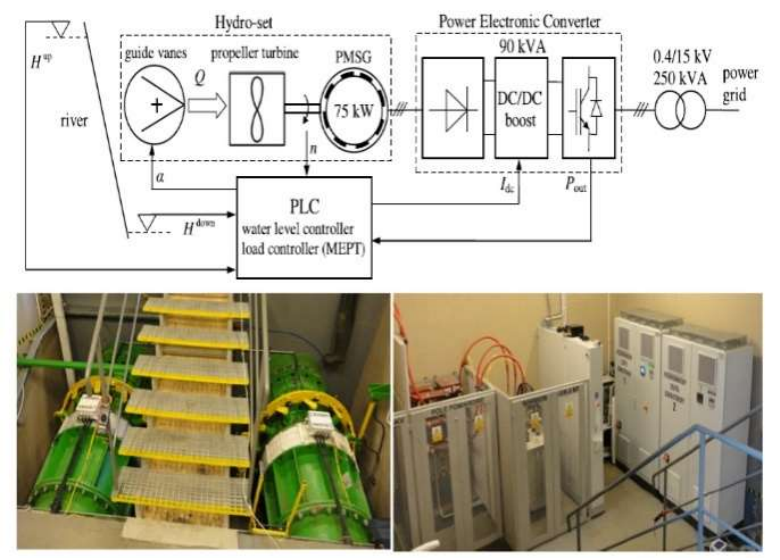

Fig. 4. Integrated propeller turbine with a synchronous generator with permanent magnets operating at variable rotational speed - AKWA Power Plant on the Biała Głuchołaska River near Nysa (Poland)

All the solutions described above relate to the integration of a water turbine inside a synchronous generator, hereinafter referred to as full integration. The advantages and disadvantages of such a solution are presented below.

The significant advantages of integrating the turbine inside the rotor of the electric generator are the limitation of the dimensions of the hydro unit to the pipe segment as well as the lack of a drive shaft and gear (Fig. 5). Such a hydro-assembly can be placed directly in the pipe from which electric cables are led from the generator. Another significant advantage of this solution is the cooling of the electric generator by the water flowing inside its body. This ensures very good cooling conditions, which enables a significant long-term overload of the generator. This reduces the cost of making the generator. Fig. 6 shows an example of the temperature distribution of a generator integrated in a tubular structure [10] operating at a rated load. The maximum temperature of the stator housing is $36^{\circ} \mathrm{C}$. This enables continuous operation with high efficiency, 
and makes it possible to resign from mechanical ventilation of the power plant unit.
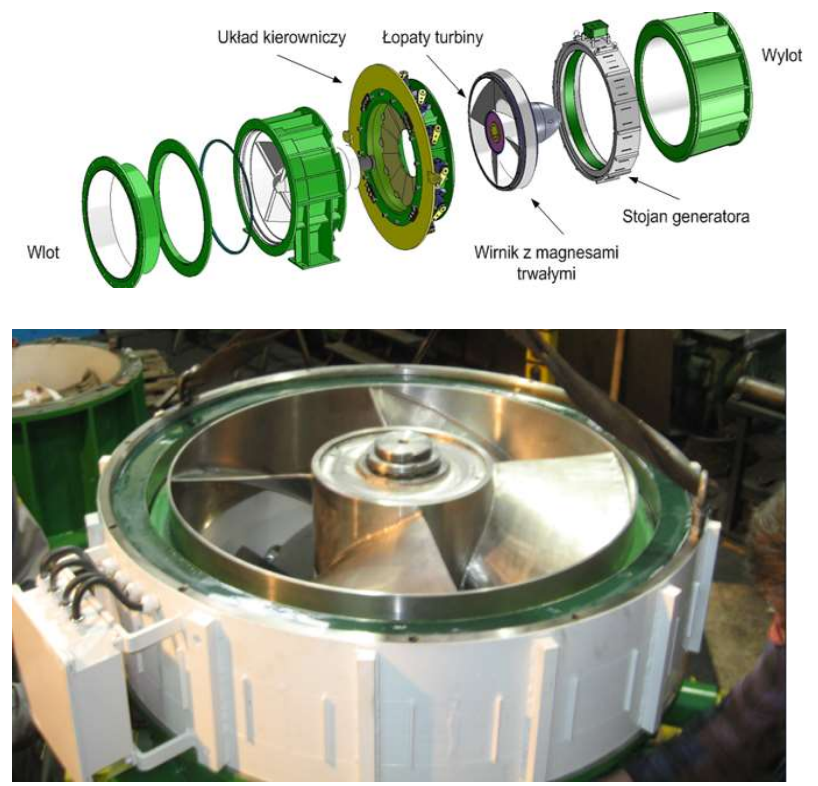

Fig. 5. Integrated water turbine with a synchronous generator with permanent magnets: a.) Components of the hydro-set, b.) Complex hydro-set [10]

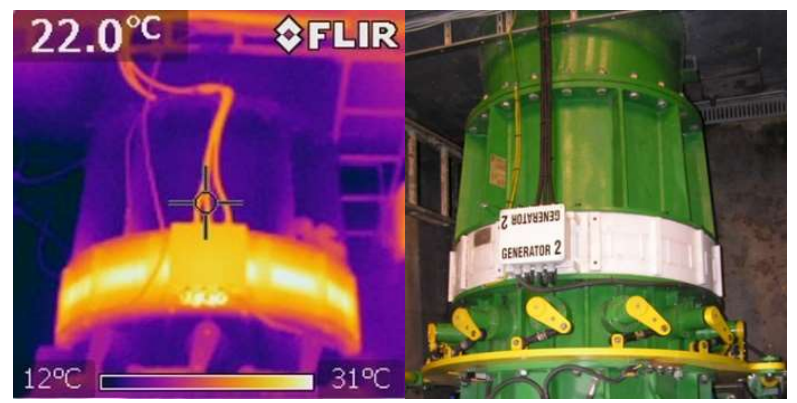

Fig. 6 Temperature distribution of the stator of the integrated hydro unit (the stator temperature at rated load did not exceed $\left.36^{\circ} \mathrm{C}\right)$

\section{3 ,Wet” Integration}

The main disadvantage of full integration are the physical phenomena related to the gap between the rotor (turbine rotor with an outer ring to which permanent magnets are attached) and the stator of the electric generator. Two solutions are used here: wet and dry gap.

A wet gap, i.e. one that is filled with river water during normal operation and does not require special sealing. However, it is necessary to seal the surface of the permanent magnets of the rotor and the stator windings. The main disadvantage of this solution is the loss of mechanical power in the gap caused by friction of water against the surfaces of the stator and rotor. The turbulent movement of water and the transport of fine fractions of impurities together with the flowing water destroys the seals. The power losses of the turbine set based on the measurements of the actual hydro set amounted to even $10 \%$ of the generator rated power depending on the size of the slot and the rotational speed of the turbine. Analytical calculations verifying the wetfracture value are presented in the article [13]. It presents a relationship (1) often used in this type of calculations, on the basis of which such calculations can be made.

$$
\Delta P=\lambda \cdot l \cdot D^{4} \cdot n^{3} \cdot 10^{-1}[\mathrm{~W}]
$$

where: $\lambda$-hydraulic resistance coefficient,

$l$ - slot length [m],

$D$ - rotor diameter $[\mathrm{m}]$,

$n$ - rotational speed [rpm].

The hydraulic loss factor (2) depends on many factors, such as surface roughness, medium temperature or the nature of the liquid flow. Its value can be determined from the Moody diagram on the basis of the relative roughness $\varepsilon$, expressed by the formula:

$$
\varepsilon=\frac{e}{\delta}
$$

where: e - surface roughness [mm],

$\delta$ - gap height [mm],

and the Reynolds number, which determines the nature of the fluid flow:

$$
\operatorname{Re}=\frac{\omega \cdot r \cdot \delta}{v}
$$

where: $\omega$ - angular velocity,

$$
\mathrm{r} \text { - rotor radius } \mathrm{D} / 2[\mathrm{~m}] \text {, }
$$

$\mathrm{v}$ - kinematic viscosity of water at $15^{\circ} \mathrm{C}$

$\left(v=1.13 \cdot 10^{-6}\left[\mathrm{~m}^{2} / \mathrm{s}\right]\right)$

Taking into account the actual dimensions of the generator: $l=0.1 \mathrm{~m}, D=0.9 \mathrm{~m}, \delta=0.005 \mathrm{~m}$ and the surface roughness of $0.01 \mathrm{~mm}$, the value of mechanical losses for various rotational speeds can be calculated (Table 1).

Table 1. Power loss calculation results

\begin{tabular}{|c|c|c|c|c|}
\hline $\boldsymbol{n}[\mathbf{r p m}]$ & 100 & 150 & 200 & 300 \\
\hline $\boldsymbol{R e}$ & 20850 & 31275 & 41700 & 62550 \\
\hline $\boldsymbol{\lambda}$ & 0.03 & 0.029 & 0.028 & 0.027 \\
\hline $\boldsymbol{\Delta} \boldsymbol{P}[\mathbf{W}]$ & 196 & 642 & 1470 & 4780 \\
\hline
\end{tabular}

The change of the Reynolds number value depending on the angular velocity does not significantly change the hydraulic resistance coefficient. It can therefore be concluded that the mechanical power losses in the gap depend on the rotational speed in the third power (Fig. 7).

For the rated operation condition, these losses are significant and constitute $6.4 \%$ of the hydro set rated power. Contamination in the water present in the gap can significantly increase the mechanical wear, increasing the erosion of the sealing materials.

The other disadvantage of the wet gap, apart from power losses, is the rapid wear of the rotor and stator seals when working with water contaminated with e.g. sand. The operation of the facility [10] showed the need to replace the sealing materials at least once a year. An example of the influence of contaminated water on the abrasion of the composite sealing the stator and rotor in a turbine integrated with a wet gap is shown in Fig. 8. 


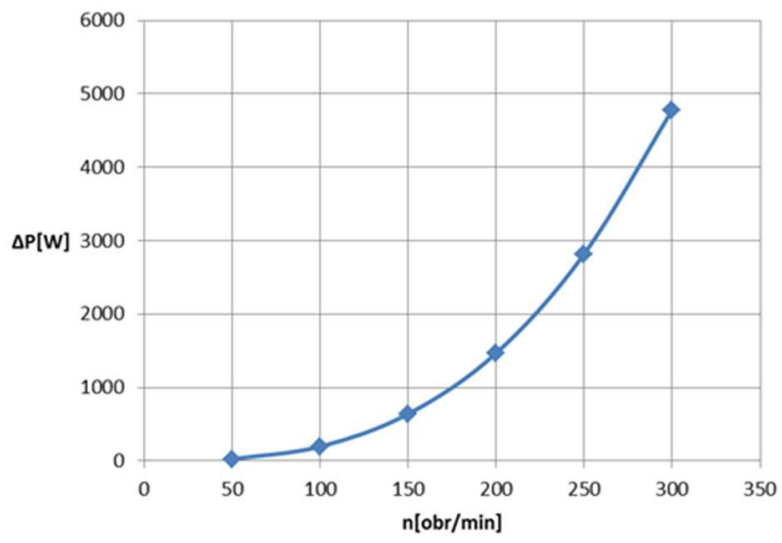

Fig. 7.Mechanical losses in the gap as a function of the rotational speed of the rotor [13]
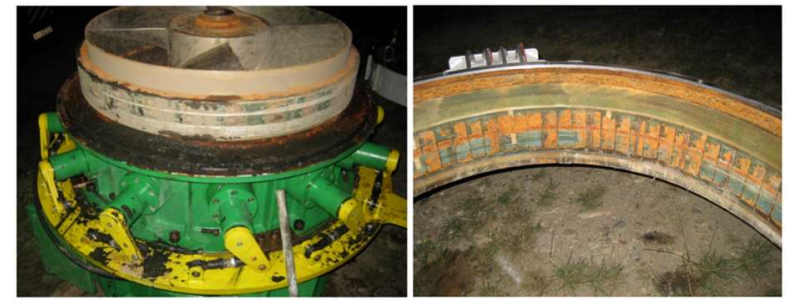

Fig. 8. An example of the influence of contaminated water on the abrasion of the composite sealing the stator and rotor in a turbine integrated with a wet gap

Another significant disadvantage of this type of solution is the gradual dampening of the generator stator windings, which reduces the electrical insulation. This can result in an electrical short circuit in the stator windings. Stator insulation burnout due to an electrical short circuit resulting from poor electrical insulation in a turbine integrated with a wet gap is shown in Fig. 9.

Furthermore, the integration of a dimensioned turbine in the rotor of a synchronous generator requires the design of the generator stator in each case. This causes increased costs of the hydro unit and makes it difficult to create a series of types of machines.
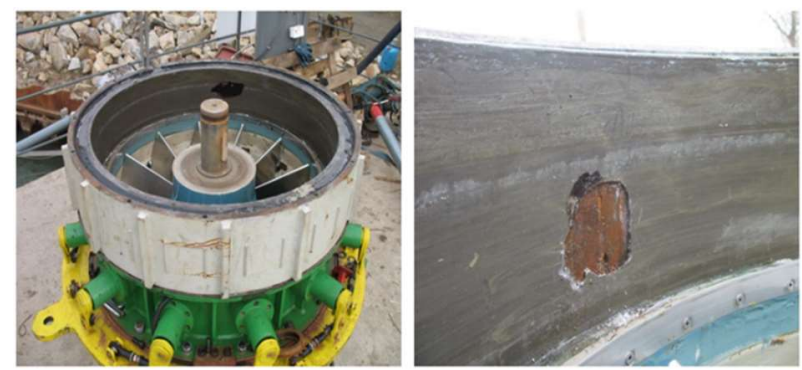

Fig. 9.Burnout of the stator insulation due to an electrical short circuit resulting from poor electrical insulation in the turbine integrated in the wet gap.

\section{4 „Dry” Integration}

Dry gap between generator stator and rotor - i.e. one in which during normal operation there is a mixture of a small amount of water and air that does not cause significant power losses. This solution is achieved through the use of a special elastic sealing system. In the
1980 s, a flexible seal dedicated to a turbine with adjustable turbine blades was developed (Fig. 10) [15].

This solution was implemented at the HPP Weinzödl power plant (AUSTRIA, on the Mur River) in 1982 with two parallel STRAFLO-Turbines with a diameter of 3.7 $\mathrm{m}$ and a total capacity of $8 \mathrm{MW}$.

This type of solution has been extensively tested by the Institute for Hydraulic Fluidmachinery at Graz University of Technology and described in the article [15] in which a $400 \mathrm{~mm}$ diameter turbine was tested at a speed of 1500 rpm (Fig. 11).

Multivariate tests were carried out to analyze power losses, the amount of leaking water, the strength of various sealing materials for different levels of water pollution and various displacements of the turbine rotor in relation to the generator.

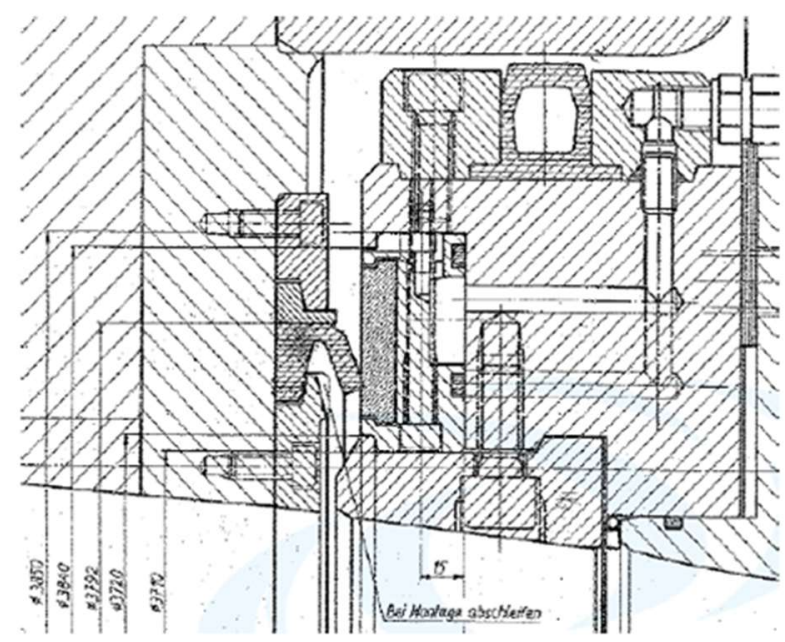

Fig. 10. Flexible sealing system proposed by HPP Weinzödl [15]

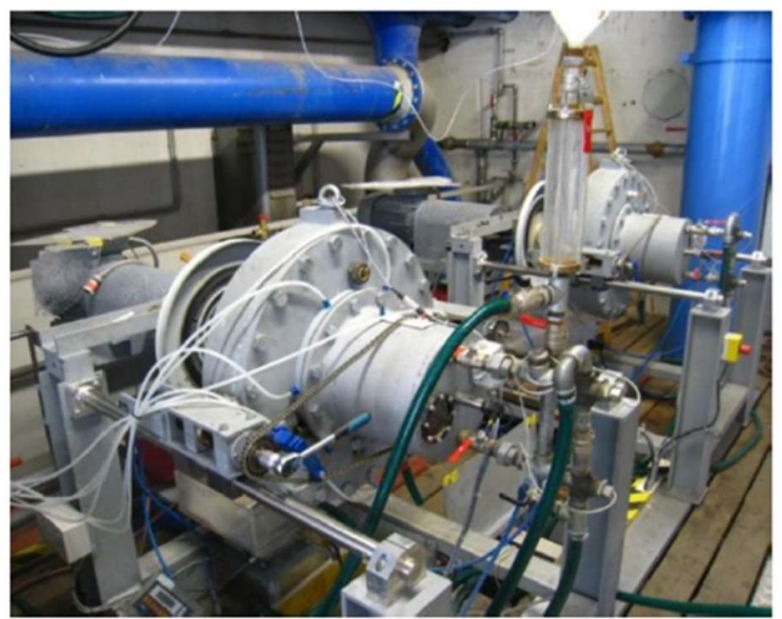

Fig. 11.Laboratory stand for testing a dry fracture in an integrated turbine [15].

Sealing tests with clean water showed a power loss of $2 \%$ and a water leakage of $0.041 / \mathrm{s}$. Water contamination with sand resulted in an almost twofold increase in power loss and water leakage through the seal. Long-term tests showed significant damage to the sealing materials (Fig. 12). 

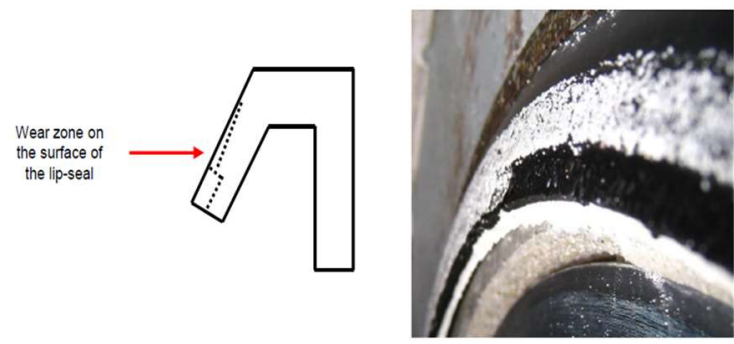

Fig. 12. An example of the destruction of the integrated turbine seal for a dry gap [15]

In order to reduce the wear of the seal, a system of cleaning the seal with pressurized water using a dedicated labyrinth was proposed. The proposed solution has served its purpose, but it is technically complicated.

\section{Conclusions}

The study presents various existing design solutions for the integration of a water turbine with an electric generator in order to enable the compact construction of a hydro unit. Technical and operational analysis of these solutions allowed to develop the direction of integration characterized by high efficiency and reliability. This was achieved through the elimination of a mechanical gear, the use of a synchronous generator with permanent magnets and an integration method that allows the elimination of water from the generator gap through an installation similar to submersible pumps.

Additionally, the implementation of various solutions of electric energy conversion systems was taken into account, on the basis of which the system using the power electronic converter was selected. This solution enables trouble-free operation of the generator with the power system and wide regulation possibilities. Variable speed operation allows for dispensing with mechanical control systems [16-17]. The advantage is the possibility of adaptive operation of the hydro unit with variable rotational speed to the conditions in the river, which will facilitate the creation of a series of types of machines. Variable rotational speed may bring additional benefits in the form of simplification of the structure of the hydro unit. The unification of machines and multiple construction of units with the same diameter significantly reduces the costs of assembly and service.

In summary, it can be stated that the integration of the turbine with a direct-drive generator for the lowest heads has a technical and economic justification. Construction investment are significantly lower than for classic solutions. The full integration is attractive because it simplify the hydroset construction and don't limits the flow cross-section. However, the problems related with power losses and electrical insulation in case of wet integration, or complicated sealing system in dry integration, limits the solutions reliability. The classical bulb housing with a synchronous generator is characterized by simpler and cheaper implementation, reliability and the lack of lubricating materials.

\section{References}

1. L. F.Harza. US1485186A, US patent (1919)

2. Krzyżanowski Turbiny wodne - konstrukcja $i$ zasady regulacji, WNT (1971)

3. H.Miller, The STRAFLO Turbine: The realisation of Harza's idea; Escher Wyss Ltd.: Zürich (1974)

4. A.Christ,Hydrostatic seals for large diameters. 9th International Conference of Fluid Sealing, Noordwijkerhout, Netherlands, 1st - 3rd April(1981)

5. H.R.Hopper; Mayer H.W.; Severn B.,Manitoba HYDRO and STRAFLO Units. 92nd E.I.C. Annual Congress St. John's, Newfoundland. 25th /26th May (1978)

6. A.Frust,Ausbau des RheinkraftwerksLaufenburg Fünf Jahre BetriebserfahrungmitStrafloTurbinen,BulletinSEV/VSE 2/98. S.25-29

7. N.Gautam, A.Rentschler, T.Schneider, A.Binder,Modeling and analysis of parallel connected permanent magnet synchronous generators in a small hydropower plant, WSEAS Trans. on Power Systems 5, 1, p. 825-830 (2006)

8. C.Xiaoli, A.Binder, and E.Schlemmer, StraightFlow permanent magnet synchronous generator design for small hydro power plants, in Proc. Int. Conf. Clean Elect. Power, May 21-23, pp. 323328 (2007)

9. J.Schiffer, H.Benigni, H.Jaberg, M.Wessiak, J.Mayrhuber, Experimental investigation of the rim-lip-seal of a double regulated STRAFLO Kaplanturbine under extreme conditions, Proceedings of the Hydro 2013 International Conference and Exhibition, Aqua Media International (2013)

10. T.Węgiel, D.Borkowski,Doświadczenia z eksploatacji MEW o zmiennej prędkości obrotowej. Zeszyty Problemowe - Maszyny Elektryczne 3/2012 (96), pp. 97-103 (2012)

11. D.Borkowski, T.Węgiel, Zarządzanie przetwarzaniem energii w małej elektrowni wodnej o zmiennej prędkości obrotowej, Czasopismo Techniczne, 24, pp. 19-32 (2012)

12. D.Borkowski, T.Węgiel,Small Hydropower Plant with Integrated Turbine-Generators Working at Variable Speed. IEEE Trans. Energy Convers., 28/2, pp. 452-459(2013)

13. T.Węgiel, D.Borkowski, D.Liszka:Efficiency analysis of an energy conversion system for a variable speed small hydropower plant,International Conference on the Sustainable Energy and Environment Development (SEED),(2016)

14. D.Borkowski, M.Węgiel, P.Ocłoń, T.Węgiel,CFD model and experimental verification of water turbine integrated with electrical generator, XI International Conference on Computational Heat, Mass and Momentum Transfer, ICCHMT2018, May 21-24 2018, Cracow, Poland (2018) 
15. J.Schiffer,Experimental investigation of the rim-lip seal of a double regulated Straflo Kaplan turbine under extreme conditions, In Promoting the versatile role of Hydro, PO Box 285Wallington, Surrey SM6 6AN, UK: Aqua Media International Ltd.(2013)

16. Status report on variable speed operation In small hydropower, Energie publication, Austria (2000) Online:http://ec.europa.eu/energy/res/sectors/doc/s mall_hydro/statusreport_vspinshp_colour2.pdf

17. D.Borkowski,Control Strategy for Maximizing Conversion Efficiency of Small Hydropower Plant, Technical Transactions - Electrical Engineering, 1-E, pp.15-24 (2015) 